\title{
Use of Nutritional Supplements Among Gym Clubs Participants in Sulaymaniyah City, Kurdistan Region of Iraq
}

\author{
Mahmood AA ${ }^{1}$, Hadi JM'1 , Maolood IQ ${ }^{2}$
}

'Department of Medical Laboratory Science, College of Health Sciences, University of Human Development, Kurdistan Regional Government, Iraq, ${ }^{2}$ Ministry of Higher Education and Scientific Research, Department of Research and Development, Directorate of Scientific Affairs, Erbil, Kurdistan Regional Government, Iraq.

\section{ABSTRACT}

Introduction: Using dietary supplements has gained interest amongst people who desire to enhance their body composition. However, there are scant published data regarding the use of nutritional supplements and gym users. This study is to assess the intake of nutritional and dietary supplements among gym members in Sulaymaniyah city, Iraqi Kurdistan.

Methods: The results of this study are based on the responses of one hundred gym members (aged over 18 years) to a self-administered questionnaire.

Results: Almost half of the sample reported taking nutritional supplements and hormones. Thirty percent of the participants were consuming different protein powders. Most dietary supplement users noticed some side effects. Supplement users should always consult their physicians and been under the supervision of professional trainers and medical practitioners to avoid any side effects such as hypertension, hepatic disturbance, kidney disorders, hepatic, kidney disturbance, and muscle pain. However, some people (gym participants) may experience allergies, upset stomach/abdominal pain, and frequent urination.

Conclusion: The usage rate of fitness supplements is very high, and the users are not aware of the potential consequences or dangers of unsupervised practice or unprescribed products. Therefore, there is an immediate need to promote consumers' awareness of this issue, and the latest scientific data must be provided to users and coaches concerning consuming supplements.

Key words: Exercise, Health promotion, Hormones, Nutritional supplements, Sulaymaniyah

\section{Introduction}

The concept of body image is now an increasing trend influenced by the media. Consequently, people have increased appearance awareness. ${ }^{1}$ To

DOI: https://doi.org/10.3126/ijosh.v11i3.39763

Conflicts of interest: None

Supporting agencies: None

Date of submission: 21.03.2021

Date of acceptance: 09.08.2021

Date of publication: 30.09 .2021

\section{Corresponding Author}

Jihad M Hadi, MSc,

University Lecturer (Polymer chemistry)

Department of Medical Laboratory of Science

College of Health Sciences, University of Human Development

Sulaimani, 46001, Kurdistan Regional Government

Iraq

Tel. +9647702177501

Email: jihad.chemist@gmail.com achieve the desired body image, people must have good diets, adequate rest, and active exercise programs. ${ }^{2}$ Some athletes use nutritional supplements to improve their performance. ${ }^{3}$ Several dietary supplements, usually come in different food forms, including tablets, capsules, powders, or pills, are available on the market and can be categorized into the following groups: (I) food elements, such as proteins (II) prescription preparations, such as vitamin and mineral capsules or pills, (III) and supply of one or more concentrated nutrients, such as proteins, vitamins, minerals, and trace elements. ${ }^{4}$ People use these supplements for many reasons, including increasing the fat-free mass in the whole body (i.e., bodybuilding), general improvement of health, enhancing energy with overall performance,

\section{(c) (1) (8)}

This journal is licensed under a Creative Commons AttributionNon Commercial 4.0 International License. 
and avoiding specific diseases. ${ }^{5}$ They also use vitaminbased hormones for organized digestion; initiation, inactivation, and removal in advanced cells of the tissue, biological function exertion, and circulation release. Vitamins $A$ and $D$ is the major source of hormones. They are the first hormones discovered to affect the metabolism of the skin. ${ }^{6}$ Dietary supplements in response to exercise promote muscle tone gains after regular training. ${ }^{7,8}$ Additionally, growth hormone stimulates the accumulation of muscle protein and promotes protein synthesis by inducing ribosomal initiation and enhancing translation. ${ }^{9}$

The use of hormones and supplements has become more widespread around the world and it is especially worrisome because many research studies have shown that many people consuming these improvements did not seek any medical advice in advance. ${ }^{10}$ In pursuit of being stronger, many weightlifters consume unproven, potentially harmful, or even prohibited nutritional supplements. ${ }^{4,10}$ Using dietary supplements has grown among teenagers over the last two decades. Creatine has been self-reported as one of the most commonly consumed dietary supplements. ${ }^{11}$ Although there are data to support the potential craving for sports drinks, caffeine, and creatine, most of the alleged nutritional supplements have not been defended or verified by scientific studies that they boost athletic performances. ${ }^{12}$ Inappropriate uses of these products or contamination may cause possible health issues, and athletes may be at risk of violating anti-doping regulations. ${ }^{12,13}$ The usage rate of various nutritional supplements and hormones has publicly been reported worldwide. However, there are scant published data on the general use of these fitness products by the members of the gym in Sulaymaniyah, the Kurdistan Region's intellectual capital. Thus, the study assesses the knowledge and attitude towards nutritional intake among the gym members in Sulaymaniyah city. This research marks a pivotal point in evaluating participants' knowledge and attitudes to nutritional supplements and hormones and offers reliable data and accurate information to gym members. The objective of this study is to evaluate the usage of dietary supplements by fitness club members with potential influencing factors. In addition, it determines the relationship between levels of knowledge and the specific variables like participants' awareness of the various side effects of nutritional and protein supplements.

\section{Methods}

This is a cross-sectional study using self-administered questionnaires to collect data. We have followed the methods of Yasser $^{10}$ and conducted the survey in six randomly picked gyms in Sulaymaniyah based on availability and coordination of the gym owner. This city had been chosen because it is known to promote the pursuit of intellectualism and it is well-recognized that health, beauty, and fitness are of great concern to its citizens. The gyms are situated in the city center. Written consent has been obtained from the gym officials who decided to take part in the study. We have presented to oversee the dissemination and selection of questionnaires to answer any questions from the participants.

For data collection, a pre-designed survey, a closeended questions had been used. If required, the participant could have chosen more than one response. The questionnaire consisted of five main parts: First, social and demographic statistics, including age and education; second, the participants' work out details on time and pace of the exercises; third, concerns about the kinds of available vitamins and hormones, why the respondents took them, and where they bought them; fourthly, concerns about the origins of their knowledge of dietary supplements and hormones, the explanations for their consumption, and the estimated price; fifth and last if the participants benefited from using these products.

Consciousness about dietary supplements and hormones' side effects was also investigated, and whether participants experienced any harmful effects. Possible health risks of dietary supplements and hormones have been reported. Participants provided their views as follows: "Yes," for a potential side effect, and "No," for no-side effects, or "I do not know." Responses to "no" or "I do not know" about identified side effects were deemed inaccurate for lack of understanding or sensitivity. Data and statistical analyses were recorded using GraphPad Prism (GraphPad, USA). Descriptive statistics were calculated, such as percentages, means, and standard deviations

\section{Results}

To the best of our knowledge, no similar work has been published in the context of the Kurdistan Region 
of Iraq and it is the only study up to date that shows and analyzes the use of nutritional supplements by the gyms' members in the aforementioned context. Customer demand relating to the information sources has been discussed and also the KAP regarding consumer supplements has been assessed. This research has been conducted in Sulaymaniyah to consider the mindset of visiting a specialist gym to using supplements. The researchers of this study distributed questionnaires throughout several wellknown local gyms. Out of 100 athletes studied, more than half used various nutritional supplements throughout the course. The background characteristics of the participants are illustrated in Figure 1 and Table 1. A total of 100 interviews have been conducted. The study appears to mainly involve the young; most of the participants $(60.2 \%)$ are between the ages of 18 to 26 . More than half of the participants received Bachelor's degrees (56.75\%); (42.2\%) were smokers. The majority $(67.15 \%)$ did not have a particular diet, and their body weights were normal. Thirty-eight percent of the participants $(38.8 \%)$ had been playing sports for over a year. About half of the participants regularly go to gyms 3-5 days a week. More than three quarters $(82.8 \%)$ did exercise for 1-2 hours per day.

More than a quarter of the participants reported back taking dietary supplements. More than $30 \%$ of them used protein powder. Participants mentioned taking vitamins, sports drinks, high-carbon chocolate bars, fat burners, and extreme weight supplements. Figure
1 illustrates the ratios of dietary supplement forms taken by participants. Regarding providing information, instruction, and awareness of food supplements, nearly half of the participants (49\%) received the required information from their healthcare providers, and $(23 \%)$ received it from the internet. In comparison, friends $(17 \%)$ and coaches $(11 \%)$ had less impact on the participants' experience.

A high number of participants (48\%) received bodybuilding nutrients. A few of the participants stated that they took them to increase results, lose weight, or avoid diseases [Figure 2]. The patterns and motivation to use supplements in our study community were also different. Females were more likely to take nutritional supplements for general health advantages across all gym locations, whereas males used them to enhance performance and strength.

Figures 3 and 4 illustrates participants' knowledge of nutritional supplements and hormones' different side effects. Supplement users experienced widespread weight gain, stomach pain, and intensified urination, possibly because colleagues shared their encounters with athletes. These results confirm the hypothesis that a gym atmosphere plays a vital role in gaining knowledge with supplementation. In general, most of the gym attendees we're not aware of most of the side effects of nutritional supplements, such as high blood pressure, liver disease, kidney disease, allergies, and muscle pain. More than half of the participants stated that they had reached their dietary supplement goals.

Table 1: Statistics on demographic characteristics, period, and level of human activity in the gyms in Sulaymaniyah and using hormones and dietary supplements

\begin{tabular}{|c|c|c|c|c|}
\hline \multirow{2}{*}{$\begin{array}{l}\text { Statements } \\
\text { Age }\end{array}$} & \multicolumn{2}{|c|}{$\begin{array}{l}\text { Use nutritional supplement } \\
\qquad(n=54) \mathrm{N} \%\end{array}$} & \multicolumn{2}{|c|}{$\begin{array}{l}\text { Do not use a nutritional supplement } \\
\qquad(n=46) \mathrm{N} \%\end{array}$} \\
\hline & & & & \\
\hline $18-25$ & 31 & 57.40 & 29 & 63.3 \\
\hline $26-30$ & 11 & 20.37 & 10 & 21.7 \\
\hline $31-40$ & 10 & 18.51 & 6 & 13 \\
\hline$>40$ & 2 & 3.70 & 1 & 2 \\
\hline \multicolumn{5}{|l|}{ Education } \\
\hline Intermediate & 3 & 5.55 & 4 & 8.69 \\
\hline High school & 16 & 29.62 & 13 & 28.26 \\
\hline Bachelor & 32 & 59.25 & 25 & 54.34 \\
\hline Master & 2 & 3.70 & 3 & 6.52 \\
\hline Above master & 1 & 1.85 & 1 & 2.17 \\
\hline \multicolumn{5}{|l|}{ Smoking status } \\
\hline Smoker & 21 & 38.8 & 21 & 45.65 \\
\hline Nonsmoker & 33 & 61.11 & 25 & 54.35 \\
\hline
\end{tabular}




\begin{tabular}{|c|c|c|c|c|}
\hline \multicolumn{5}{|l|}{ Body mass index (BMI) } \\
\hline Underweight $(<18)$ & 2 & 3.70 & 3 & 6.53 \\
\hline Normal weight (18-24.99) & 35 & 64.81 & 32 & 69.56 \\
\hline Overweight (25-29.99) & 17 & 31.48 & 11 & 23.91 \\
\hline \multicolumn{5}{|l|}{ The total period of exercise } \\
\hline$<1$ month & 3 & 5.55 & 4 & 8.69 \\
\hline From 1 month to 6 months & 15 & 27.7 & 13 & 28.26 \\
\hline From 7 months to a year & 9 & 16.6 & 18 & 39.13 \\
\hline More than a year & 29 & 53.70 & 11 & 23.92 \\
\hline \multicolumn{5}{|c|}{ Frequency of exercise per Week } \\
\hline$<3$ times & 11 & 20.37 & 8 & 17.39 \\
\hline 3-5 times & 29 & 53.70 & 25 & 54.34 \\
\hline$>5$ times & 14 & 25.92 & 13 & 28.27 \\
\hline \multicolumn{5}{|l|}{ Time of daily exercise } \\
\hline$<1 \mathrm{~h}$ & 1 & 1.85 & 1 & 2.17 \\
\hline $1-2 \mathrm{~h}$ & 44 & 81.48 & 39 & 84.8 \\
\hline$>2 \mathrm{~h}$ & 9 & 16.66 & 4 & 13.03 \\
\hline \multicolumn{5}{|l|}{ Following a special diet } \\
\hline Yes & 40 & 74.07 & 15 & 32.6 \\
\hline No & 14 & 25.92 & 31 & 67.4 \\
\hline
\end{tabular}

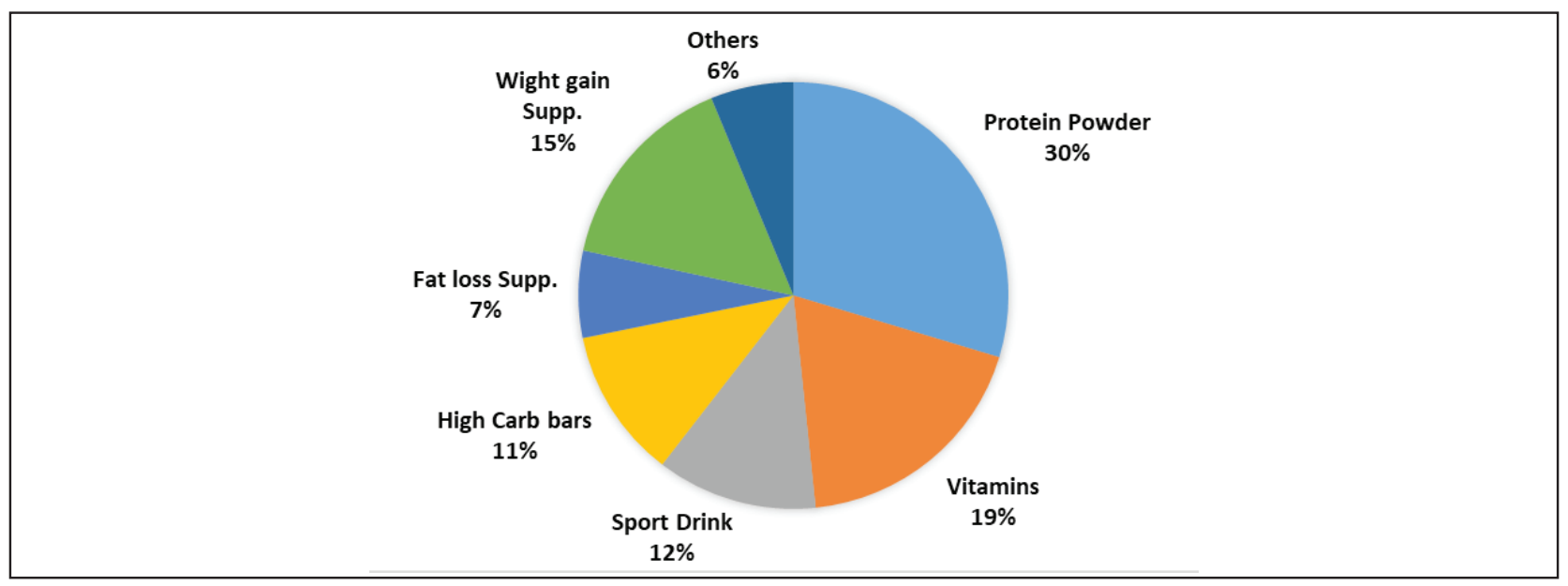

Figure 1: Forms of nourishment supplements used by study participants

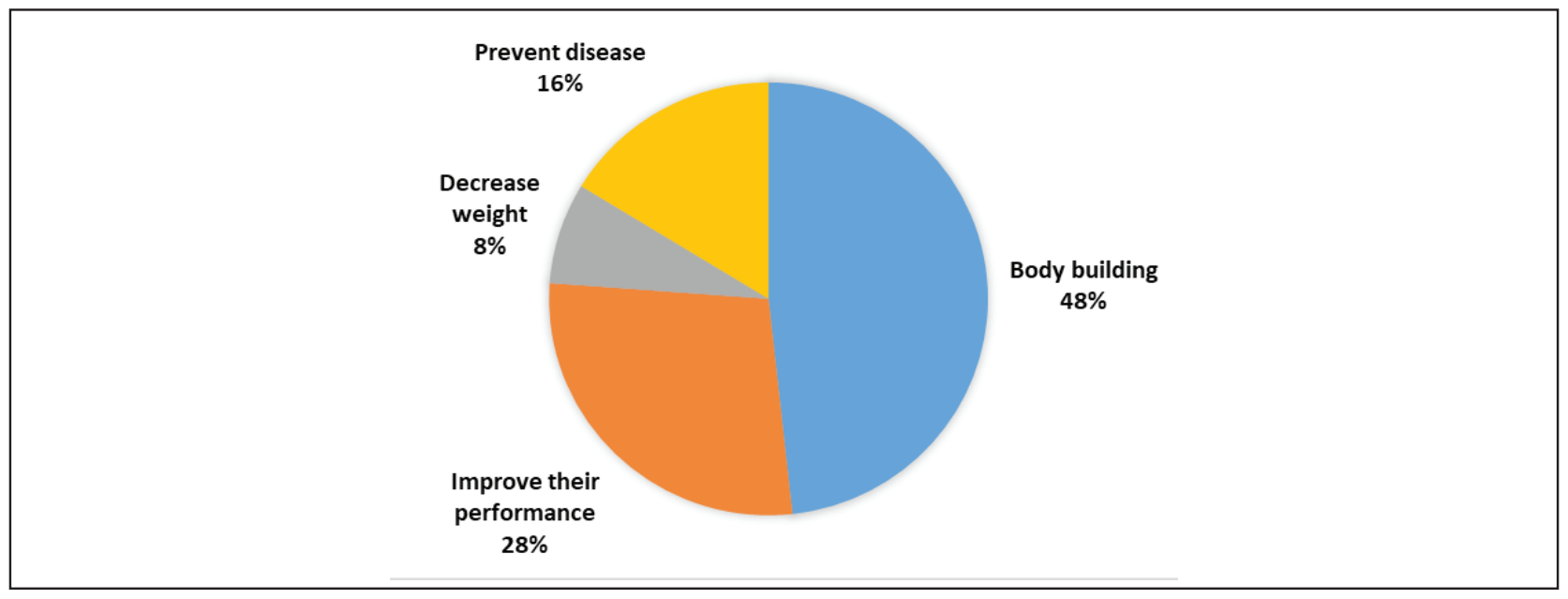

Figure 2. Reasons for the use of nutritional supplements by study participants 


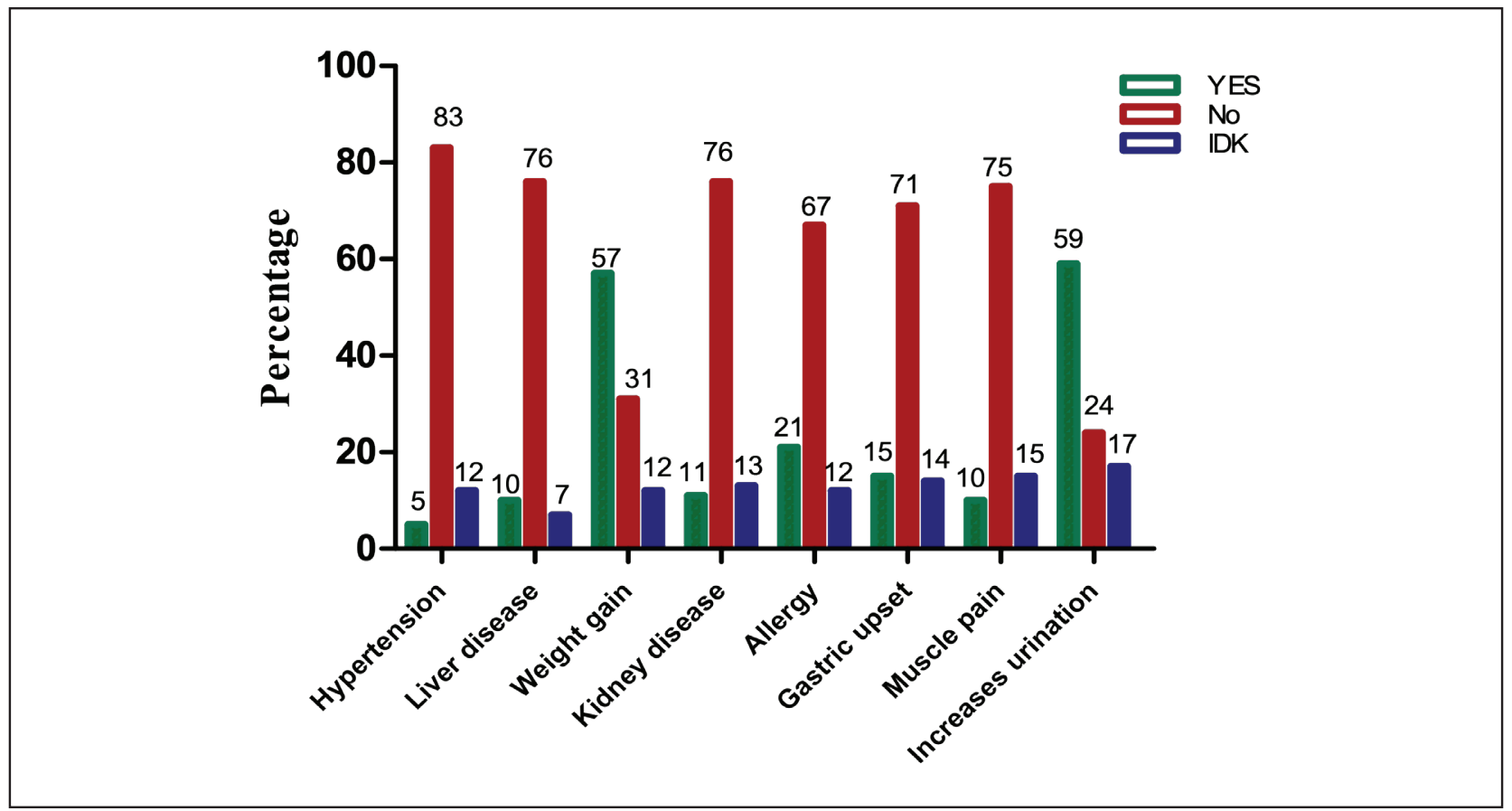

Figure 3. Participants' awareness of the different side effects of nutritional supplements

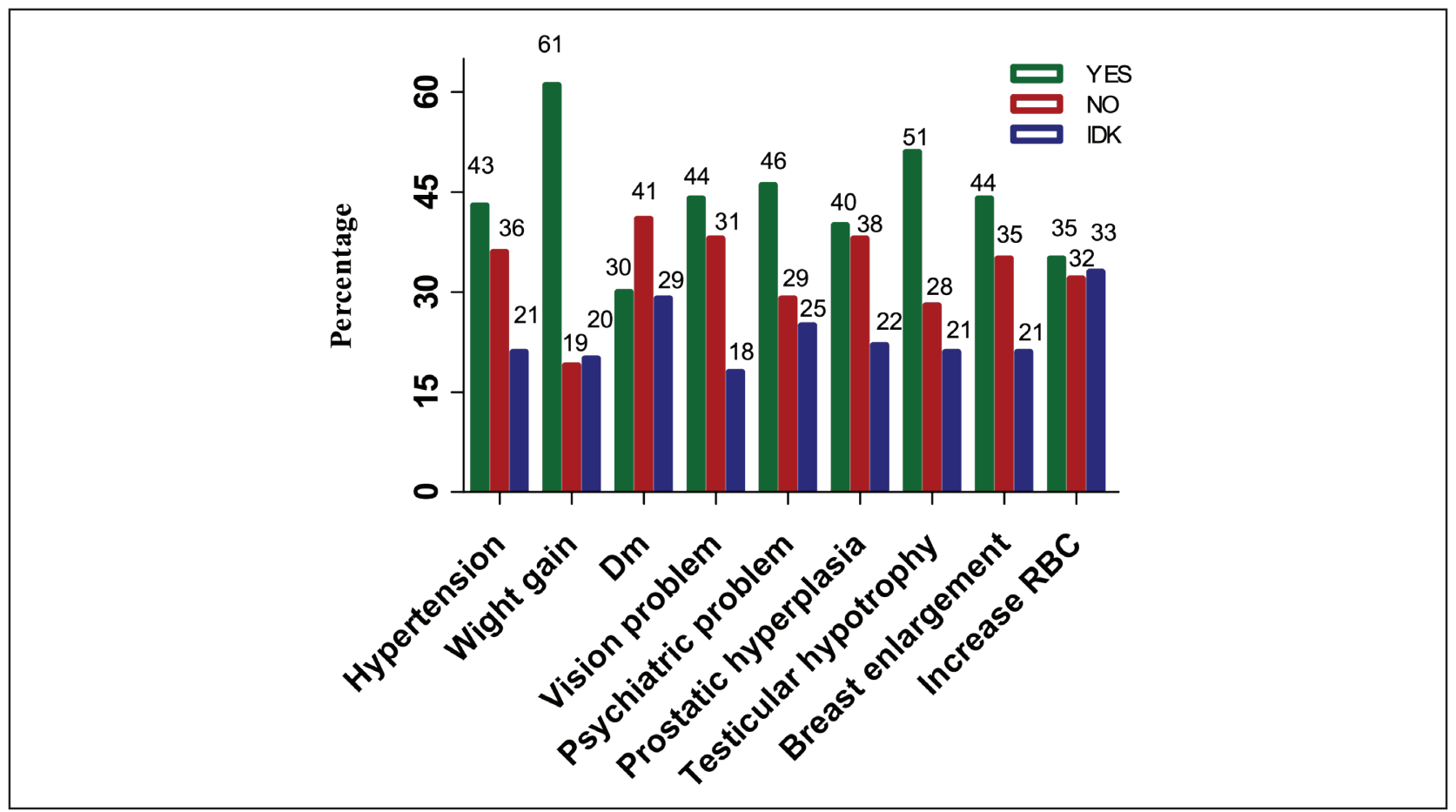

Figure 4. Participants' awareness of the different side effects of the hormones used

\section{Discussion}

This study found that protein powder was the most frequently used form of nutritional addition while a research study on football players in Tehran showed that carbonated beverages and vitamins were the most popular ones. ${ }^{14}$ This distinction may be attributed to several reasons that this study group has accepted dietary supplements. This study is similar to the one conducted in Beirut discovering that dietary supplements were mostly used for bodybuilding. ${ }^{15}$ While various studies showed that people who do exercises in gyms frequently do not require nutrient supplements, many participants feel that the supplements play an integral part in enhancing their nutritious supplements. ${ }^{16}$ Health 
food stores $(37 \%)$ were the most common source of these nutrients, followed by friends, coaches, the internet, and private pharmacies. ${ }^{17}$ This study has also found that friends were the most popular source of providing hormones. We have noticed that the fitness environment hugely influenced participants' decisionmaking and they agreed that the use of vitamins and hormones will have a positive impact on training coaches, the training of fitness professionals, and general understanding. According to the data we have got from different sources, we discovered that using the supplements under the supervision of a trained master coach seems to have no adverse side effects. However, in some cases, they might cause allergy, gastric upset, and frequent urination. Users might also face these issues such as hypertension, weight gain, vision problems, psychiatric problems, prostatic hyperplasia, testicular hypotrophy, breast enlargement, increased RBC, and even death. Therefore, hormones should be used reasonably and thoughtfully under the supervision of registered dietitian nutritionists and certified coaches. Based on our findings, we proposed that health providers should raise questions about dietary supplementation or hormone usage while they take patients' medical history. We further proposed that coaches take compulsory courses to become certified trainers. This will help to regulate their activities and prevent dietary supplements and hormones abuse. There is a need to increase public awareness of the value of physical exercises, maintaining healthy diets, and proper use of dietary supplements. One researcher found that doctors were the most common nutritional supplement source amongst participants. ${ }^{17}$ This is inspiring optimism, as physician's instructions and statements are scientifically supported and more reliable than newspapers, relatives, or friends. The findings of this study encourage offering training courses to health care providers about nutritional supplements because patients want their physicians to be confidents, knowledgeable, skilled, and respectful. Consistent with the findings of other surveys, this study also confirmed that the most popular advertisement sources for dietary supplements were healthcare providers, the internet, T.V., and magazines. ${ }^{18}$ As the most credible source of knowledge, healthcare providers must be mindful and willing to ask pertinent questions and provide users with information on dietary supplements. Advice from healthcare professionals' dietary supplement users should be directed towards reliable information sources and directions on assessing dietary supplement use and reporting a harmful event. In addition, consumers of dietary supplements can begin to learn about supplements from a credible, reliable, evidence-based source of knowledge, such as physicians or pharmacists rather than looking for information from less reliable and readily available sources, such as T.V. or internet advertising. A study in Beirut, Lebanon, found that the prevalence of dietary supplement use in fitness club members was 36.3 percent. ${ }^{15}$ The main purpose of using these supplements was to increase muscle strength and efficiency. Protein powder was the most common substitute for participants. A study in Tehran, Iran, found that the prevalence of dietary supplements among health club participants was around $66.7 \%$. Just a limited number of participants $(0.5 \%)$ took illegal substances. ${ }^{19,20}$ About $11.2 \%$ of the participants of this study took supplements and banned substances. The researchers observed that male participants were more likely to use barred substances than female members. ${ }^{20}$ This is because these supplements were mainly advertised to cause male muscle growth. ${ }^{21}$ This research participants lack knowledge, medical advice, and evaluations (see Figure 4). A high percentage of people taking hormones in the current study may have had some side effects. However, the adverse effects of hormones did not cause significant discomfort to prevent users from taking them. Many of the subjects were not conscious of the side effects of the hormones. Hormone users have a greater awareness of weight gain, anxiety issues, red blood cell counts, and swollen prostate as potential side effects. Therefore, they had less awareness of high blood pressure, diabetes, defective vision, gynecomastia, and testicular deficiency. This paper has explored the prevalence of hormones and dietary supplements among people who exercise in gyms in Sulaymaniyah and presented the most common types of supplements to ascertain the main motives for using these products. However, this research has some limitations. First, it involves a crosssectional analysis and gave only a snapshot of the usage of the participants about hormones and dietary supplements during the survey. Another drawback is the gym samples which were not taken evenly-since there are more gyms in the city center relative to other districts so it cannot be generalized. And lastly, close consideration is needed before concluding because obtaining a smaller sample than estimated, may lead to inaccurate results.

Because of the COVID-19 pandemic disease, many of the participants were unable to go to the gym, and 
currently, all the gym clubs are closed, and consequently, we were unable to obtain further samples.

\section{Conclusion}

This work presented a cross-sectional study to highlight dietary nutrient and hormone prevalence in gyms in Sulaymaniyah. We found that most of the gymgoers used food supplements, mostly recommended by practitioners. The study participants also lack knowledge, medical advice, and evaluations in the research participants. The findings have substantiated that nearly half of the samples used food supplements

\section{References}

1. Yamamiya Y, Cash TF, Melnyk SE, Posavac HD, Posavac SS. Women's exposure to thin-and-beautiful media images: Body image effects of media-ideal internalization and impact-reduction interventions. Body Image. 2005;2(1):74-80.

2. Yarasheski KE, Zachwieja JJ, Bier DM. Acute effects of resistance exercise on muscle protein synthesis rate in young and elderly men and women. American Journal of Physiology.1993;265(4) : 28-34.

3. De Ravin SS, Naumann N, Robinson MR, Barron $\mathrm{KS}$, Kleiner DE, Ulrick J, et al. Sarcoidosis in chronic granulomatous disease. Journal of Allergy Clinical Immunology. 2008; 122(6): 1097-1103.

4. Darvishi L, Askari G, Hariri M, Bahreynian M, Ghiasvand R, Ehsani S, et. al. The use of nutritional supplements among male collegiate athletes. Int J Prev Med 2013;68 (4).

5. Campbell WW, Leidy HJ. Dietary Protein and Resistance Training Effects on Muscle and Body Composition in Older Persons. J Am Coll Nutr. 2007;26(6):696-703.

6. Reichrath J, Lehmann B, Carlberg C, Varani J, Zouboulis CC. Vitamins as hormones. Horm Metab Res. 2007;39(2):71-84.

7. Kraemer WJ, Häkkinen K, Newton RU, NindI BC, Volek JS, Mccormick M, et al. Effects of heavy-resistance training on hormonal response patterns in younger vs. older men. J Appl Physiol. 1999;87(3):982-92.

8. Hansen S, Kvorning T, Kjær M, Sjøgaard G. The effect of short-term strength training on human skeletal muscle: The importance of physiologically elevated hormone levels. Scand J Med Sci Sport. 2001;11(6):347-54.

9. Godfrey RJ, Madgwick Z, Whyte GP. The exerciseinduced growth hormone response in athletes. Sport Med. 2003;33(8):599-613. and hormones. Out of 100 athletes studied, more than half used various nutritional supplements throughout the season. Most of the participants $(60.2 \%)$ are between the ages of 18 to 26 . The majority $(67.15 \%)$ did not have a particular diet, and their body weights were normal. And thirty-eight percent of them had been doing sports for over a year (38.8\%). Protein powder had been consumed by $(30 \%)$ of the participants. The primary justification for taking dietary supplements was to build muscle. Health authorities play a crucial role in setting and assessing necessary quality requirements in the sports facilities in terms of internal environment credibility, safety exercise, and coaches' competencies.

10. Khojah YY. Prevalence of Using Hormones and Nutritional Supplements among Gym's Trainee in Saudi Arabia. Egypt J Hosp Med. 2018;73(5). Available from : https://ejhm.journals.ekb.eg/ article_16174.html.

11. Jagim $A R$, Kerksick $C M$, Creatine Supplementation in Children and Adolescents, Nutrients. 2021;13(2):664.

12. MalikA, Malik S. Prevalence of nutritional supplements in gyms. Br J Sports Med. 2010;44:44.

13. Luong KVQ, Nguyen LTH. Organic arsenic intoxication from bird's nest soup. Am J Med Sci. 999;317(4):26971. Available from: http://dx.doi.org/10.1016/S00029629(15)40520-8

14. Alowais MA, Selim MA, E-H. Knowledge, attitude, and practices regarding dietary supplements in Saudi Arabia. J Family Med Prim Care 2019;8 (2): 365-72.

15. Aljaloud SO, Ibrahim SA. Use of dietary supplements among professional athletes in Saudi Arabia. J Nutr Metab. 2013;245-49

16. Lukaski HC. Vitamin and mineral status: Effects on physical performance. Nutrition. 2004;20(7-8):63244.

17. Ishihara J, Sobue T, Yamamoto S, Sasaki S, Tsugane S, Ogata J, et al. Demographics, lifestyles, health characteristics, and dietary intake among dietary supplement users in Japan. Int $\mathrm{J}$ Epidemiol. 2003;32(4):546-53.

18. Alhomoud FK, Basil M, Bondarev A. Knowledge, attitudes and practices (KAP) relating to dietary supplements among health sciences and nonhealth sciences students in one of the universities of United Arab Emirates (UAE). J Clin Diagnostic Res. 2016;10(9Available from : https://pubmed.ncbi.nlm. nih.gov/27790468/

19. El Khoury D, Antoine-Jonville S. Intake of nutritional supplements among people exercising in gyms in Beirut city. J Nutr Metab. 2012. Available from : https://pubmed.ncbi.nlm.nih.gov/22506105/. 
20. Saeedi P, Mohd Nasir MT, Hazizi AS, Vafa MR, Foroushani AR. Nutritional supplement use among fitness club participants in Tehran, Iran. Appetite. 2013;60(1):20-6.
21. Ruano J, Teixeira VH. Prevalence of dietary supplement use by gym members in Portugal and associated factors. J Int Soc Sports Nutr. 2020;17(1):1-8. 